\title{
The Plan and Design of Organic Joint of New and Old Urban Areas: Kaifeng City, Henan Province as an Example
}

\author{
L.W. Huang ${ }^{1, ~ a ~ a n d ~ W . J . ~ W a n g ', ~ b ~}$ \\ 1,2School of engineering and architecture, Xinjiang university, Urumqi, China \\ aemail: huanglw1990@163.com, bemail:wangwanjiang@126.com.
}

\begin{abstract}
Keywords: Organic joint. Joint area. Kaifeng. Plan and design.
Abstract. In the expansion of urban size, the joint between the new and old urban areas is an important guarantee for improving the construction of urbanization, and is the key to improve the quality of the city and the only way to the development of new urbanization in China. Based on planning and design and update of connection area between Kaifeng city and west as an example, the paper studies the plan from region, ecology, population, culture, transportation and economic development to explore the connection of the old and new areas, and the effect on whole city. The plan and design to join new old city according to local conditions, make to connect both areas will organically combine a historical and cultural heritage of the ancient city and the modernization of the new city. In combination with the heritage and development of traditional architecture and culture, the protection of the traditional ancient city, and the plan and construction of the city will benefit from those as references.
\end{abstract}

\section{Introduction}

Since the three decades' of reform and opening-up, now China has been transforming from a poor and backward agricultural country towards an important period of state-building accompanied with the rapid economic development and the drastic modernization. China has also stepped into the completion of the decisive stage of building a well-off society in an all-round way. The new urbanization construction is considered as a critical period of the further development. Over the course of the reform era, China's urban population increased from 170 million in 1978 to 730 million in 2013. The land urbanization rate increased from $17.9 \%$ to $53.7 \%$, which has entered ranks of the urbanization rate of more than $50 \%$, increasing by $1.02 \%$ per year on average [1]. Although the starting point of the urbanization in our country is low, the pace of development process is really fast; however it caused some issues like how to keep the sustainable development of urban construction, the imbalance between "land urbanization" and "population urbanization", unreasonable spatial distribution and structure, low level of management and service, inefficient protection of natural, historical and cultural heritage, the defects of characteristic in urban construction, and the deficient connection between the old and new urban areas after the expansion of the city. How to continue the historical style and features of the old town, and seamlessly integrate the new and old city by showing the characteristics of city as a whole is, and always is, the subject that we must pay attention to in the development of city renewal. It will also helpfully boost the urbanization construction to a new stage of the development which mainly aims to enhance the quality and the transformation in China [2].

At present, academic research is mainly focusing on the old city reconstruction, old city protection and various kinds of garden or new city planning and design. The research on studying the cohesion between the new and old city is scanty, and what's more, most of them concentrated on the improvement of the public transportation, but and ignored the specific measures, strategy and practice. Taking the transition and cohesion between the old and new urban area after the urban spatial expansion of the old town as an example, this paper explores the ways to solve the cohesion of the old and new in the old city reconstruction in an ancient city during its.

\section{Necessity of the Plan and Design of Joint of New and Old Urban Areas}

Concept. New district consists of two types of districts: "newly build type" and "incorporated type". The former is composed of early development zone, industrial park or the new extension of land 
development. It is always close to the old city, and part of the suburbs. The latter one is formed during the old city extension and it is usually near the county or town incorporated. It is part of the outer suburbs. In regards of the process they formed, new urban area can be categorized as "dislocation developmental type", "extended type" and "core zone transfer type".

Necessity. After the urban expansion, there are significant difference between the old city and the new district because of the years of construction, subordinate relations, space layout, construction materials and methods of construction. The new areas are generally lacking of public service facilities to meet urban requirement (such as medical treatment, education, transportation, livability, etc). Hence the urban construction quality was low which also leads to the urbanization lagging behind industralization seriously [3]. So, making the new and the old connecting well in the first place, preserving the styles and features of the old, transferring the culture and service to the new, that's the only way to joint the two areas together and enhance the quality and the standard of the city.

\section{Planning and Design Strategies of Joint of New and Old Urban Areas}

The planning and construction of the joint areas are unable to escape in the course of planning and design the new-type urbanization, old urban development and new urban construction as well. Standing at the whole city's interest perspective, the planners should break the bond of the region concept and implement the strategy in a unified way, using and planning the lands under unification, so as to make the transportation, the tourism, the culture and entertainment, the industry structure and the liable conditions in "multi strategies develop simultaneously" (Fig. 1). All of these will be eventually realize the new ecological city.

Adjust Measures to Local Conditions. The planning and construction of joint area between new and old city should be combined with theirs original architectural features characteristics and geomorphological features, combined the local residents living habits with economic basis to avoid blind. The planners should take the eco-environment protection as the core and consider the surroundings in a long term under the premise of using uncultivated land rather than the cultivated land, improve the efficiency of using land. To deal with the original value of the buildings and terrain conditions to be used, and avoid redundant construction and short-lived architecture. Using high technology, underground parking and underground facilities and other means to take advantage of overground/underground space, and improve the city's comprehensive functions.

Inheriting the Culture. All of the city's urban culture is refined in its long development process, including the "obvious culture" and "invisible culture". One of the most representative and the most intuitive "obvious culture" is the city's traditional architecture and the overall style. It reflects the soul of the whole city, it can be built. "Invisible culture" refers to the local residents living habits, customs, religious beliefs and so on. It was formed gradually and can never be produced. Therefore, in the urban construction especially the plan and design of the joint area, we should put effort to build the former extending to the latter, highlighting the characteristics of the city, and create a city card.

Human-Oriented. "People" is not only the builders of the city, but also the residents of the city. At present, China's urbanization rate of the household registration is only about $36 \%$, far below the $80 \%$ level of the developed countries, and lower the $60 \%$ average level of the developed countries of the similar to China's per capita income [1]. The current circumstances are , the population urbanization is far behind the land urbanization. The demographic devidends are gradully declining or draining, so it's hard to gather a large amount of people in a short period, so there have been many empty cities or ghost towns after expansion. Forming the linkage between the old and the new with human-oriented is the only way to improve the quality of the city and attract more people. Eliminating the barriers of the household registration system, transferring the current settlement policy, declining the obstacles of floating population, is the only way to boost the population urbanization effectively.

Convenient Traffic. Traffic has been influencing and changing our life all the time. It is the important basis for the development of a city and a region, which also is an important symbol of the comprehensive development level for the whole area. The layout of transportation determines the development of a city. It's a key tool for external conmmunications and has a great impcat on the scale of the whole city and the spatial organizations as well [4]. Throughout the urban development 
history in the world, it is not difficult to find that convenient transportation can make the whole city and region rise sharply, otherwise it will gradually decline. People should consider the convenience of the traffic with three-dimensional, reticulated and omnibearing sight.

Sustainable Urban Development. That refers to develop coordinated with three pillars (environment, economy and society). It refers to not only meet the needs of people without prejudice to future generations the ability to meet the demand and making the modern people live better under the premise that do not harm the interests of future generations. Taking the benefit of the current and the future into consideration. The basic principles is protecting the non-renewable resources, getting the most from renewable resources and reusing resources [5]. In the process of developing economy, society and the urban areas, people should protect resources and environment to make every single part of the city linked well and then get a sunstainable development of green city.
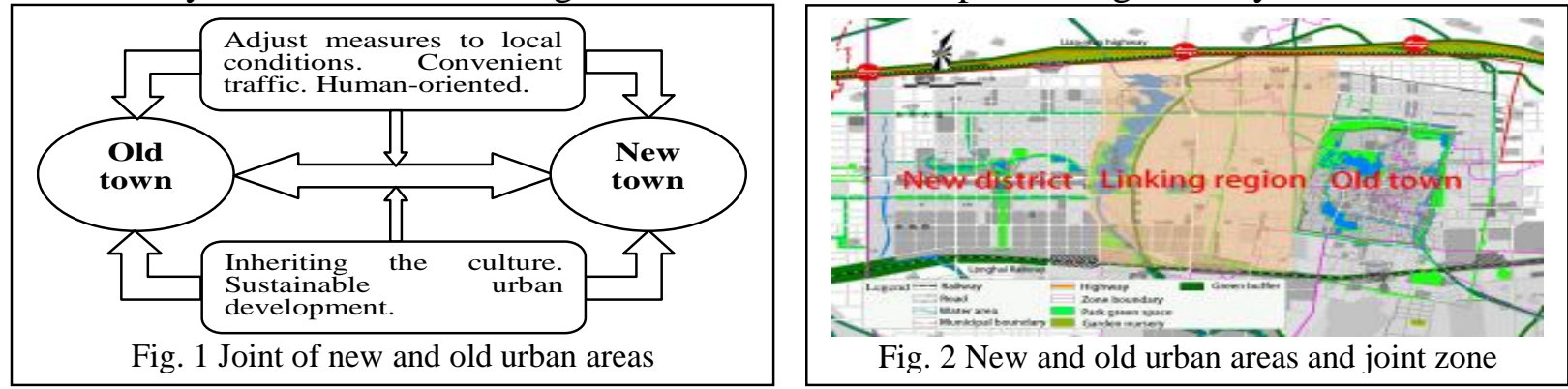

\section{The Planning and Design Practice of Joint Zone of New and Old Urban Areas of Kaifeng City}

Joint Zone Overview. The ancient Kaifeng city had undergone a period from prosperity to decline, therefore so much ancient elements subsided. There are buried deep in the underground "city upon city" and phenomenon of which the city axis "Zhong shan road" ( $8 \mathrm{~m}$ below the ground is the north-south axis of Dongjing Yujie or say, Royal street, numbers of the Kaifeng cities in different times deposit, however the axis stays unchanged) is the only unchanged axis of a city for a thousand years in the world. Above the ground, there are a large amout of the remains and repaired relics in nowadays. The core part of the city is the internal part of the complete ancient city wall.

The area is located in the west of Kaifeng, from western city wall of the ancient city of Kaifeng in the east, to the first street of Kaifeng new district in the west, south to the Longhai railway, Lianhuo expressway in the north, and covers an area of about $44.24 \mathrm{~km}^{2}$. This area belongs to the western suburbs township of Kaifeng. There are many small villages, barren fields, moat outside the city walls, flood protection, flood control reservoirs (Heigangkou regulating reservoir) and historical remains of ancient city underground, etc. With the processing of urbanization, urban expanded unorderly in everywhere, Kaifeng is no exception. Since 1992, more than ten years after the reform, Kaifeng began expand the urban area. But for various reasons, the progress wasn't fast until the concept that Zheng-Bian integration submitted and Zhengkai boulevard opened in 2006 which also indicates the important place of cohesive zone (Figure 2).

Planning and Design Strategy and the Contents. Basing on the regional characteristics of Kaifeng and connecting the joint parts as a concept to formulate the planning target. Taking the executive office, education and scientific research, comprehensive services, leisure and recreation, convenient traffic, living community and "human-oriented" as the theme; taking the "culture + " as the driving force to undertake to the charm of the ancient city to drive new city flourished as the core, to create a new ecological binding region, organic joint of new and old city in Kaifeng.

"Adjust Measures to Local Conditions, Emphasize Ecology" to Create a Livable City. The joint area is around to Jinming avenue, or say, the sub-axis, located in the geometric center of Kaifeng's west region. It plays a role in connecting the East and the West. Due to the need of green development, it is necessary to design the joint area, which can not only link up the new to the old, but also has the significance of the "continuation of the ancient prosperity today" (Table 1). 
Table. 1 Four zones and connection effect

\begin{tabular}{|c|c|c|c|c|}
\hline Zones & New urban area & Joint area & Old urban area & Connection effect \\
\hline North zone & $\begin{array}{l}\text { Scientific } \\
\text { research of } \\
\text { vocational } \\
\text { education }\end{array}$ & $\begin{array}{l}\text { West campus of } \\
\text { Henan university }\end{array}$ & $\begin{array}{l}\text { Area of colleges } \\
\text { and universities }\end{array}$ & $\begin{array}{l}\text { Scientific research collaboration, make } \\
\text { full use of resources, leading the } \\
\text { construction and development of the city. }\end{array}$ \\
\hline $\begin{array}{l}\text { Secondary } \\
\text { north zone }\end{array}$ & The water park & $\begin{array}{l}\text { Kaifeng west lake, } \\
\text { pearl tower }\end{array}$ & $\begin{array}{l}\text { Massage the } \\
\text { scenic spot }\end{array}$ & $\begin{array}{l}\text { Through Jin Yao road traveling special } \\
\text { line, connecting the main scenic area, } \\
\text { highlight brilliant ancient style. }\end{array}$ \\
\hline $\begin{array}{l}\text { Secondary } \\
\text { South zone }\end{array}$ & Business CBD & Jinming square & Gulou business & $\begin{array}{l}\text { Through girder door to realize a line of } \\
\text { business services, convenience to } \\
\text { people's livelihood. }\end{array}$ \\
\hline South zone & Industrial zone & $\begin{array}{l}\text { Government } \\
\text { agencies, the } \\
\text { business enterprise }\end{array}$ & $\begin{array}{l}\text { South of the city } \\
\text { industry }\end{array}$ & $\begin{array}{l}\text { Relying on the Longhai railway and } \\
\text { logistics channels, convenient business } \\
\text { services and government macroeconomic } \\
\text { control. }\end{array}$ \\
\hline
\end{tabular}

"An axis, a horizontal line and four zones". An axis is Jinming road which is the sub-axis. A horizontal line is Daliang road i.e. Zhengkai boulevard for connecting the east and the west. Four zones are: north zone of scientific research and education, secondary north zone of cultural tourism industry, secondary southern zone of financial business, south zone of office and comprehensive service. Four zones play a corresponding and functional structure of space area.

Take full advantage of topography to rebuild original buildings. For history and development reasons, there are a certain numbers of urban villages in joint area with poor conditions, narrow streets, congested traffic. The construction and development of the whole city has very big effect. Planners adopted various measures for migration and transformation, to build "ecological community".

With the rapid economic development and the gradually westwards urban framework, the TV tower located in the outskirts of city has slowly changed inside the city, which become the focus of the new and old city. Its' radiation not only affects the life of the nearby residents, but also run counter to the green development theme. Rebuild the tower on the basis of the cancellation of the signal emission function, and turn it into a pure landmark with a "urban core, urban park, urban complex" position. The tower will be multi-functions which includes shopping, conference and exhibition, etc. Stressing ecology will make the tower as a "bright pearl in central plains".

Reproduce the original royal garden "Jinmingchi" ruins of the Northern Song Dynasty and with the slogan that "remerge the millennium magnificent dream in one night" to create one of the eight best views in Bianjing, namely, "waterscape over night in Jinmingchi lake".

Heigangkou regulating reservoir is adjacent to the west city dike. It became a multifunction project which combined ecological landscape, agricultural irrigation, public water usage, flood control and drainage together as Kaifeng west lake. It plays an important role in improving the environment, living conditions. In the mean time it helps achieving "six rivers, five lakes connect ten scenic spots" scenic region and makes the city with $7.48 \%$ water area live up to the North Watertown's reputation.

"Cultural Inheritance, Manifestation of Character" Continue the Prosperous of the Ancient City. There are nine emperors (168-year-rule) in northern Song Dynasty which is a period of great power and splendors in history. The spreading of Song culture exactly embodies that. As the mayor of Kaifeng puts it: "The movement of the capital didn't take the history and culture away". Following the step of the Tang dynasty, later generations carrying the Song culture for thousands years. The typical culture feature are "architectural culture", "food culture", "folk culture" and "citizen culture", etc.

Kaifeng ancient "architectural culture" with symmetrical layout, tidy streets, magnificent majestic palace, as the characteristics, with emphasis on building groups combined with natural and cultural, represent national integrity. The religion and reservation are different from western values through monomer building aesthetic personality. It is an inalienable important component in Chinese ancient buildings, which is our guide. It is the reference of modern architecture, also is an integral part of the world's architectural culture art. The constructing was mainly used wood, and regard the brick, tile, stone as supplementary materials. In appearance, the building consists of three parts, the upper roof, 
the middle pillar and three foundation supports in which "bracket system" is the most unique element in eastern architecture artifacts. No matter the pillars or eaves, the design is orderly and clear arranged which also reflects the "dominant culture" of feudal regime. The reconstruction buildings on the original sites such as Jinmingchi, Xiaosongcheng (a landmark building) and Kaifeng north station are designed in antique shape which is also an expression of Kaifeng ancient culture and its continuity.

Since ancient times, the food culture in Kaifeng is shining with dazzling brilliance, "five tastes reconcile" and "the theory of heat control" by YI Yin occupies a vital position in the cooking culture in China. It's the footstone of Chinese cooking. Today Kaifeng's delicacies, still adhere to the "five tastes reconcile, soup raises fresh" concept. Food court of Jinan-road, Xiaosongcheng are seen as the representatives in the joint area, especially the street culture of "the night market" which has became unique scene in Kaifeng drawing tourists enchanted by the charming.

"Convenient Traffic, Expansion of Space" Build a Regional Transportation System. There is no doubt that the convenient traffic is closely bound up with a city's vicissitude. Jinming avenue, the sub-axis, is the core of the joint area. By using it, can create a "three circles and a net" transportation system, and build a transport network with smooth traffic both internal and external ( Fig. 3).

Through north-south, in the south, the axis reaches the Songcheng station which belongs to Zhengkai intercity railway and the entrance of Zhengmin motorway from which people can get to Zhengzhou Xinzheng International Airport directly, therefore opening up a traffic corridor achieving the convenience between the provincial capital and the air harbour. In the north, it reaches the north station of Zhengxu high-speed railway station and the entrance of Lianhuo motorway. All of these forms a 3 5 hours traffic circle outside the province and a 1 3 hours the traffic circle in the province.

With four crosses inside the city (the national road 310, Zhengbian logistics channels, Zhengkai boulevard, Zhengbian traffic corridor), Zhengzhou and Kaifeng can get in touched within one hour.

Planning and constructing urban arterial routes with complete underground/aboveground facilities, fast channel, three-dimensional transportation so as to upgrade the road standards and smooth the break road gradually. What's more, construct Line 1 and Line 2 tramway and transpotation grid which will fully connect the new and the old and promoting the seamless joint in urban roads.

"Adjusting the Industry, Driving Economy" to Promote the Steady Development of the City. Economic development is the foundation of urban construction. The prosperity of a city indicates developed economy. The economic development cannot leave the industry alone. To adjust, transform and upgrade industry, can boost the economic development. It also make it possible for the prosperity of a city. The original industrial structure has already been formed basically which is taking modern agriculture as the foundation, manufacturing industry as a pillar, new industries as a guide and modern service industry as the lead. Then on this basis, economic structure should be optimized in a further way. Promoting traditional industrial upgrading, cultivating rising industries with two engines driving force so as to develop agriculture, foster manufacture, get the service industry bigger and then give a impetus to the fusion of high-tech and traditional industries. When developing three industries, the service sector, especially cultural industry, should be stressed for it will accelerate regional culture and relative industries [6]. Developing culture tourism industry and creating new highlights are not only a national economic strategy planning, but the diction of the development of Kaifeng as well. Organizing a series of Qingming Festival activities, building the pearl of Kaifeng cultural tourism industrial park will promote the economic level. What's more, it plays an important role in cultivating rising industry as well as enhancing the economic level in a steady pace.

It is not hard to see from Figure 4, that since the concept of Zhengbian integration had been put forward in 2005, Zhengkai boulevard had been available in 2006 and the construction of the new district in Kaifeng, especially the gradually implement of the joint area under the lead of "culture+", Kaifeng's GDP and the growth rate has been significantly promoted ranking in the third place among the whole province in 2015. The performance was the best level in modern and it also took the lead in the province to form "3. 2. 1" pattern for the development of the industry [7]. 


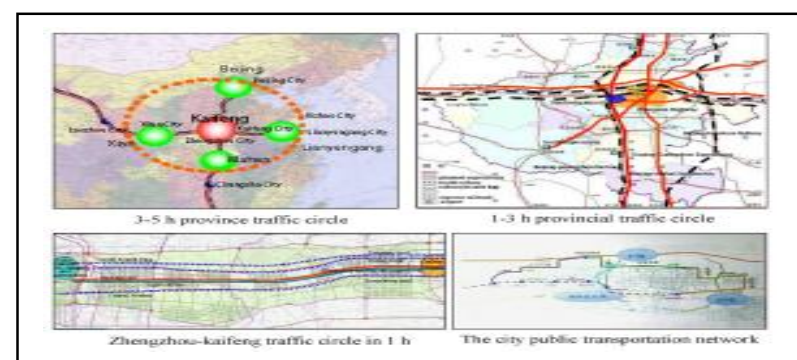

Fig. 3 "Three times a net" regional traffic system

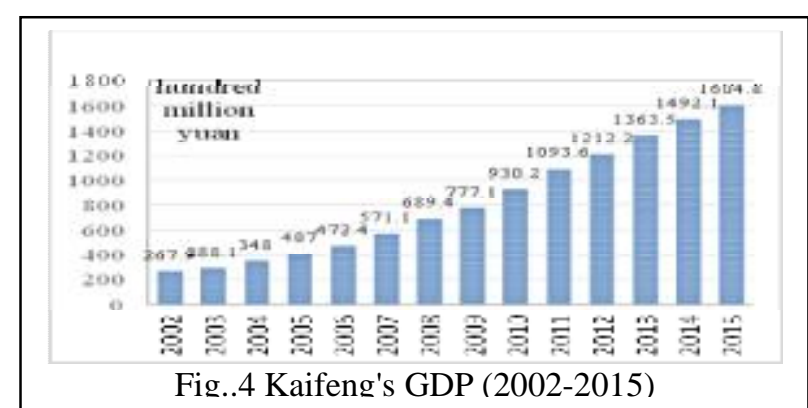

Fig..4 Kaifeng's GDP (2002-2015)

"Quality Improvement, Continuous Development" Establish a Prosperous Sub-Center City. To strengthen ecology environment protection, people should conserve energy, reduce emissions, observe the red line for protecting the environment strictly and execute the project with blue sky and clear water. By selecting non-polluting enterprises, eliminating and ameliorating those polluting firms, transferring radiation of the TV tower, perfecting shanty towns and urban villages, treating sewage and garbage, improving rain water pump station and so on, make the city infrastructure more completely. With the completion of Zhongyi lake and the gorgeous Kaifeng west lake landscape, the Royal River system can be perfected gradually with which the city will be clean, beautiful and livable. The grade of the whole city can be elevated and people should have a home with trees and lakes.

Stressing the construction style of "new Song feng", it shoud be create a charming city with "classical extrinsic appearance and fashionable intrinsic character". Aiming at benefiting the public and maintaining harmony, people should fan out to the whole society from small part, quicken the step of reconstructing the urbanization, joint areas and alleyways so as to upgrade the social security level and improve social service system for the aged. And finally, to make the goal of sub-center prosperous city come true and establish a Kaifeng city with strong power, cultural deposits, fairness and happiness in a green sustainable development way.

\section{Conclusions}

After the urbanization and the enlargement of the city, new areas and the old especially the districts with a certain historical and cultural background of the ancient city must have some differences. Based on local features, urban culture, people-oriented, adjust measures to local conditions and highlight the characteristics of urban planning and design concept, in addition to the keynote that should not destroy the original style and features of the old city, explore a new method to plan and design of cohesion between the new and the old. Trying to avoid the phenomenon that "the different styles over a city" and "thousand cities with one single visage". This paper takes the planning and the design of the joint areas in Kaifeng as an example, elaborates the city taking "an axis, a horizonal line and four zones" as a pattern and the "Song culture" as the theme, transfering the ancient characteristics, rebuilding original buildings and sublime topography in ecological approach, creating a "three circles and a net" convenient regional transportation system, adjusting the industry to drive the economy and the prosperity of urban city fusion. Finally people realize a new green city of sustainable development.

\section{References}

[1] State Council: Rural Work Communication (2014). 06, p. 32

[2] J.Q. Yang and Y. Du: City Planning Review Vol. 40. 01, p. 72

[3] S.M. Yao, P.Y. Zhang and C. Yu, etc: Scientia Geographica Scinica Vol. 34, p. 641

[4] L. Wang and M. Deng: Urban Pr oble ms (2003). 01, P. 25

[5] G. Haughton. et al: Sustainable cities (Jessica Kingsley Publishers, London 1996).

[6] Y.P. Sun: Planners Vol. 31. 08, p. 70

[7] Kaifeng municipality: Work Report of Kaifeng Municipality (2003-2016). 